\title{
Designing and Developing an e-Portfolio for Second Language Learners in Higher Education
}

\author{
Wirawati Ngui, Vincent Pang, and Wendy Hiew
}

\begin{abstract}
This study highlights the development of e-Portfolio as a writing assessment in an advanced English language course for undergraduate students at a public university in Malaysia. The e-Portfolio was developed using an instructional design model known as ADDIE (Analyse, Design, Develop, Implement, Evaluate). A pilot test that involved 43 students was conducted in the Develop stage and qualitative data were gathered using open-ended questionnaires to determine the e-Portfolio's impact. The pilot test findings proved that the e-portfolio was functional and operating as intended. The students responded positively to the e-Portfolio features with the exception of the peer preview. The findings also revealed that a majority of the students voted for e-Portfolio to continue to be implemented in the future. The study serves as a reference for instructional designers who are keen to introduce new educational tools in the language classroom. It also established that the e-Portfolio is a promising assessment tool for second language learners in higher education.
\end{abstract}

Index Terms-E-Portfolio, ADDIE, ESL, assessment, e-learning.

\section{INTRODUCTION}

In recognition of the fact that English language mastery is one of the primary conduits for employability in Malaysia [1], English language courses are generally compulsory across Malaysian universities. At Universiti Malaysia Sabah (UMS), English language courses are offered to all the undergraduate students as part of their degree programmes. One of the advanced courses, Academic Reading and Writing, is offered to students who attained results of Band 3 and above in the Malaysian University English Test (MUET). In this course, paper portfolio was previously implemented to assess the students' writing skills. In line with the growing need to embrace technology in language learning, the electronic portfolio (e-Portfolio) was introduced to replace the paper portfolio as part of the course assessment. Nevertheless, meticulous application of technology is important in order to complement learner needs which are to a certain extent largely context dependent. Therefore, a purposeful

Manuscript received January 5, 2019; revised March 13, 2020.

Wirawati Ngui and Wendy Hiew are with the Centre for the Promotion of Knowledge and Language Learning, Universiti Malaysia Sabah, Kota Kinabalu, Sabah, Malaysia (e-mail: wirawati.ngui@ums.edu.my, wenhiew@ums.edu.my).

Vincent Pang is with the Faculty of Psychology and Education, Universiti Malaysia Saah, Kota Kinabalu, Sabah, Malaysia (e-mail: pvincent@ums.edu.my).
e-Portfolio needed to be developed to address the issue of English language mastery within the Malaysian tertiary education context. This study revealed the steps for developing an e-Portfolio for second language learners based on the instructional design model known as ADDIE.

\section{REVIEW OF LITERATURE}

\section{A. E-Portfolio}

Greenberg [2] likens the concept of portfolios to those practiced by artists, in which pieces of work are gathered in a structured manner over time. These pieces (both unfinished and finished products) serve as a basis for discussion thus allowing the artists to receive constructive feedback from others; they also serve as future reference thereby prompting self-reflection and the setting of upcoming directions. The e-Portfolio is a modernized version of portfolio. It comprises an individual's collection of evidence that demonstrates their abilities and attainments, and can be stored on a website or in a portable storage device such as a CD-ROM or DVD-ROM [3], [4]. The e-Portfolio is a valuable educational tool due to its ability to capture and support the interactive process of learning especially from the role of the learner [4].

Despite the fact that e-Portfolios evolved from paper portfolios, various distinctive features set the two apart [4], [5]. In comparison, the e-Portfolio has the upper hand in terms of mobility, accessibility, sustainability, and viewership; it also includes a range of multimedia artefacts, inculcates reflection, and allows assessments to be done both formatively and summatively [6]. An e-Portfolio also boasts greater flexibility as it can be easily revised, transferred, and navigated as compared to paper-based portfolios [7]. Additional advantages of the e-Portfolio include inexpensiveness and user-friendliness [2].

While the term e-Portfolio is used interchangeably with webfolio or digital portfolio in certain contexts [3], Love, McKean and Gathercoal [8] believe that e-Portfolios differ from webfolios. It has however been contended that the difference is minor and revolves mainly around webfolios' association with internet availability which e-Portfolios may not necessarily have. Webfolios therefore can be considered as a subset of e-Portfolios given that they include all the aspects of e-Portfolios with the added feature of internet accessibility [4], [7]. Greenberg [2] believes that e-Portfolios should ideally be accessible via the Internet. This study acknowledges the proposition that "digital", "web" and "electronic" portfolios all refer to portfolios containing a purposeful selection of digital materials which represent and demonstrate the owner's attainments; these portfolios are 
enhanced by the use of technology and are customarily accessible via the Internet.

\section{B. The ADDIE Model}

Instructional design (ID) refers to a repertoire of organised procedures to design educational programmes in a valid manner [9] and to develop ideal instructional tools based on relevant theories [10]. Therefore, ID models serve as guiding standards for the systematic development of instructional activities [11] and basing one's planning on an ID model can help create more reliable instruction [9].

ADDIE is a five-stage ID model that guides designers or developers in producing and developing instructional content and tools [12], [13] and the model is widely used in educational contexts [10], [14]. Examples of ADDIE-based research include the development of games and mixed reality training for learning purposes [15], an intelligent mobile learning tool (i-MoL) for learning grammar [16], a problem based learning mobile application for Islamic education [17] and an interactive digital educational TV programme in a Chinese university [18].

The first stage of the ADDIE model is Analyse and it is critical for helping to determine the most appropriate intervention based on context [10], [12], [14]. The main component of this stage include identifying the target group and their present knowledge, the learning context, instructional challenges as well as objectives [11]. This step focuses on the target group and aims to differentiate between the learners' present knowledge and their desired performance toward the end of the course [12].

The second stage of ADDIE is Design whereby the focus is developing methods to deliver the instruction. Sharif and Cho [11] explained that the tasks, lessons, resources as well as learning goals are developed in this stage. It is also critical that course objectives and assessments are aligned at this stage [12], [19].

The third stage of ADDIE is called Development. From planning, the designer's role now transitions to producing [12]. The content should be established with the integration of relevant technologies at this stage [11]. The product however will need to undergo a series of testing. As such, actual samples of the content and materials are to be created with the aim of testing them to determine their suitability based on feedback from relevant parties such as the designer's' superiors and students [10].

The fourth stage is Implementation and involves the execution of the plan. At this stage, the instructors and learners receive training with regard to the proposed technologies within the learning context [11]. Peterson [12] highlighted the need for designers to play an active role at this stage by continuously looking to improve the product promptly rather than letting it run its own course.

The final stage of ADDIE is Evaluation whereby the designers attempt to assess the extent to which the new design has achieved its purpose. The evaluation can be both formative and summative in nature [11]. At this stage, several key matters must be addressed which include ascertaining whether the objectives have been achieved, the impact of the course, and necessary improvements to be made in the future [12].

\section{DeVeloping THE E-PortFolio}

When designed with the appropriate purpose and features, an e-Portfolio has the potential to be more than a storage space [7]. The researchers of this study therefore aimed to develop an e-Portfolio that served as an enhanced writing assessment for second language learners, thus replacing the existing paper portfolio in the Academic Reading and Writing course at UMS. The e-Portfolio was developed with reference to the ADDIE guidelines prescribed by Branch [14], as shown in Table I. Although each stage of ADDIE is prescribed with a set of recommended procedures, flexibility is permitted as the procedures and sequence are dependent on the respective designer's viewpoint as well as the context. With this in mind, the common procedures served as the primary guidelines for the development of the e-Portfolio in this study with some minor modifications where relevant.

TABLE I: COMMON INSTRUCTIONAL DESIGN PROCEDURES ORGANISED BY ADDIE

\begin{tabular}{|c|c|c|}
\hline Stage & Concept & Common Procedures \\
\hline Analyse & $\begin{array}{l}\text { Identify the possible } \\
\text { reasons for a performance } \\
\text { gap }\end{array}$ & $\begin{array}{ll}\text { 1. } & \text { Validate the } \\
\text { performance gap } \\
\text { 2. }\end{array}$ \\
\hline Design & $\begin{array}{l}\text { Verify the desired } \\
\text { performances and } \\
\text { appropriate testing } \\
\text { methods }\end{array}$ & 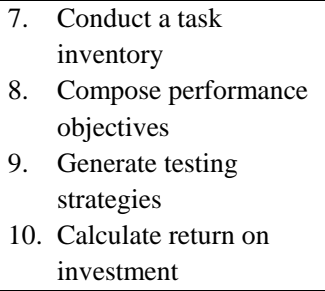 \\
\hline Develop & $\begin{array}{l}\text { Generate and validate the } \\
\text { learning resources }\end{array}$ & $\begin{array}{l}\text { 11. Generate content } \\
\text { 12. Select or develop } \\
\text { supporting media } \\
\text { 13. Develop guidance for } \\
\text { the student } \\
\text { 14. Develop guidance for } \\
\text { the teacher } \\
\text { 15. Conduct formative } \\
\text { revisions } \\
\text { 16. Conduct a Pilot Test }\end{array}$ \\
\hline Implement & $\begin{array}{l}\text { Prepare the learning } \\
\text { environment and engage } \\
\text { the students }\end{array}$ & $\begin{array}{l}\text { 17. Prepare the teacher } \\
\text { 18. Prepare the student }\end{array}$ \\
\hline Evaluate & $\begin{array}{l}\text { Assess the quality of the } \\
\text { instructional products and } \\
\text { processes }\end{array}$ & $\begin{array}{l}\text { 19. Determine evaluation } \\
\text { criteria } \\
\text { 20. Select evaluation tools } \\
\text { 21. Conduct evaluations }\end{array}$ \\
\hline
\end{tabular}

Source: Branch [14]

Thematic analysis was employed to analyse the qualitative data that were collected in this study. Thematic analysis is an approach to identify and analyse patterns in qualitative data [20] and can be used to examine experiences that are narrative based [21]. All of the data were imported to NVivo 12 and analysed with reference to the data analysis procedures advocated by Braun and Clarke [22]. As a start, the collected data were read and re-read to observe 
interesting points and identify patterns of meaning. After familiarising with the data, initial codes were generated by organising and labelling data that were meaningful. At this point, all of the data were studied and extracts were coded for potential themes that may become applicable at a later time. Having completed the initial coding, the focus then shifted to interpreting and organising the themes in relation to the coded data. The themes were re-evaluated by reviewing the coded data for each theme, followed by reviewing the proposed themes. This was done by reconsidering the coherence and relevance of the prior analysis, then merging or separating themes where applicable. At this phase, re-coding was also done when the researchers perceived that alternate codes were more appropriate or when data were left out in the initial coding. Following this, the themes were illustrated by providing a detailed explanation for how they relate to the research aim. Although the explanation for the thematic analysis of this study was clarified in a step-by-step manner, the researchers reverted to previous phase(s) when necessary to re-code the data and review the themes.

\section{A. Analyse Stage}

In this stage, data were collected to ensure that the e-Portfolio was developed according to the context. To determine the students' performance gap, open-ended questionnaires were distributed to a total of 69 past-semester students who had completed the course using paper portfolios as their writing assessment. The students' past work in the form of paper portfolios were also examined. Another set of open-ended questionnaires were distributed in the beginning of the new semester to 43 students who were involved in the pilot test of the e-Portfolio. The findings revealed that students required additional guidance in developing their writing skills, especially in relation to language accuracy. In addition, a total of four course instructors were interviewed to seek their expert opinions regarding the e-Portfolio, more specifically the strengths and weaknesses of its implementation. These data sources allowed the researchers to develop and refine the e-Portfolio based on the perception of the students and the instructors.

To accommodate the writing needs of second language learners, the e-Portfolio was intended to provide a better assessment experience by emphasising room for improvement in various stages of writing. Using the e-Portfolio, opportunities for sharing work and receiving feedback from peers and instructors are enhanced. In addition, the e-Portfolio was intended to provide a more authentic assessment experience as it is also in sync with the trending use of the Internet and digital resources in education. Learners can include artefacts (digital learning evidences) in their e-Portfolios, making the assessment process more interesting and relevant to them.

\section{B. Design Stage}

In this stage, the purpose is to confirm the desired performances and suitable testing techniques. The goals and performance objectives of the e-Portfolio were generated with reference to Bloom's Taxonomy of cognitive domain [23]. Since authentic test items and materials that reflect real-world learning environment are advocated, the
e-Portfolio tasks were based on actual and relevant context that students could write about. The assessment required students to explore and write about a pressing Malaysian issue that was in need of an innovative solution. Students were free to select any issue that they could relate to, and the writing process operated on a step-by-step basis whereby the students brainstormed for ideas then worked on planning the essay before eventually composing the full essay. The assignment revolved around a context that students were familiar with, and the issues were also genuine and relatable. Furthermore, the integration of artefacts as part of the writing tasks promoted the search for and use of online resources.

\section{Develop Stage}

The aim of this stage is to produce and validate the resources. These resources include the lesson content, supporting media, and guidance for the students and the instructors. The course content includes components and in-class activities that were carried out in line with the e-Portfolio. The type of media required to construct the e-Portfolio consisted of Google applications such as Google Sites and Google Docs. Guidance for the instructors and students comprised of the course syllabus, assessment details, writing templates, rubrics, and an e-Portfolio demonstration site that served as a reference for the instructors and students. Following the production of these resources, a pilot test was conducted. The pilot test was important as the data contributed to the revision of the e-Portfolio prior to the actual implementation.

The pilot test was conducted in an actual learning environment and involved a total of 43 students (26 in Class A, 17 in Class B) who were enrolled in the course. The respondents were undergraduate students from the Teaching English as a Second Language (TESL) programme and the International Relations (IR) programme. After completing the course using the e-Portfolio, an open-ended questionnaire was distributed to the students. The students were asked to provide qualitative details that illustrated their e-Portfolio experiences.

\section{Implement Stage}

The Implement stage signifies that development activities have ended, and the pilot test has concluded, thus indicating the transition to actual use of the instruction. As such, it was necessary to establish the learning setting by preparing other instructors as well as the target learners for the implementation of the e-Portfolio through training sessions. Since teachers are the chief facilitators of instruction in the classroom, they needed to be well-prepared and familiar with the e-Portfolio. As such, coaching was done prior to the commencement of the new semester. In addition, preparation to help students better engage with the e-Portfolio was done by conducting a training session within the first three weeks of the semester before the assessment commenced.

\section{E. Evaluate Stage}

This marks the final stage of the ADDIE model and aims to assess the quality of the products and processes. The data that were collected during the pilot test were thereby analysed to present an evaluation of the e-Portfolio. Findings from the open-ended questionnaire are presented in the following 
Table II.

TABLE II: FINDINGS FROM THE QUESTIONNAIRE

\begin{tabular}{|c|c|c|}
\hline Statement & Class A Responses & Class B Responses \\
\hline $\begin{array}{l}\text { The feedback and } \\
\text { marks given by my } \\
\text { instructor in my } \\
\text { e-Portfolio were helpful } \\
\text { for my academic } \\
\text { writing }\end{array}$ & All 26 answered Yes & All 17 answered Yes \\
\hline $\begin{array}{l}\text { The peer review in my } \\
\text { e-Portfolio was helpful } \\
\text { for my academic } \\
\text { writing }\end{array}$ & $\begin{array}{l}21 \text { answered Yes } \\
5 \text { answered No }\end{array}$ & $\begin{array}{l}8 \text { answered Yes } \\
9 \text { answered No }\end{array}$ \\
\hline $\begin{array}{l}\text { Providing artefacts and } \\
\text { reflections in my } \\
\text { e-Portfolio was helpful } \\
\text { for my academic } \\
\text { writing }\end{array}$ & $\begin{array}{l}25 \text { answered Yes } \\
1 \text { answered No }\end{array}$ & All 17 answered Yes \\
\hline $\begin{array}{l}\text { The use of the } \\
\text { e-Portfolio helped to } \\
\text { improve my academic } \\
\text { writing }\end{array}$ & $\begin{array}{l}23 \text { answered Yes } \\
3 \text { answered No }\end{array}$ & $\begin{array}{l}15 \text { answered Yes } \\
2 \text { did not comment }\end{array}$ \\
\hline $\begin{array}{l}\text { The e-portfolio should } \\
\text { continue to be } \\
\text { incorporated into the } \\
\text { course Academic } \\
\text { Reading and Writing }\end{array}$ & $\begin{array}{l}25 \text { answered Yes } \\
1 \mathrm{No}\end{array}$ & $\begin{array}{l}16 \text { answered Yes } \\
1 \text { answered No }\end{array}$ \\
\hline
\end{tabular}

As shown in Table II, the pilot test findings were generally positive with the exception of the peer review. The peer review recorded the highest number of negative experiences especially from the respondents in Class B.

With regard to the instructor feedback and marks that were provided in their e-Portfolios, the students explained that they were made aware of their level of performance, they knew what to improve for the subsequent task, and knowing their marks motivated them to perform better.

In relation to the peer review, the respondents described peer comments as useful and being able to explore others' e-Portfolios as beneficial. Viewing others' work also motivated them to perform better. On the other hand, a handful of students from both classes viewed the experience negatively. They attributed this to the biasness of the reviews and a lack of serious commitment from certain peers.

A majority of the students were positive about including artefacts and reflections in their e-Portfolios as the tasks led them to search for more information and helped them to better understand their topic. The students were furthermore able to use the artefacts to support their writing. According to the students, the inclusion of images and videos also made their e-Portfolios more appealing and interesting. Nevertheless, one student found it difficult to search for suitable learning evidences and therefore responded negatively to the task.

Almost all the students in both classes agreed that using the e-Portfolio enhanced their skills in academic writing. They attributed this to the feedback and comments they received, the information and artefacts that they used, and the motivation that was derived from viewing one another's work. However, three students noted that they had difficulty connecting to the Internet to access their e-Portfolios. Adapting to the e-Portfolio was also a challenge for the students as they were not familiar with the tool especially in the beginning of the course.

On the whole, almost all of the respondents expressed that
e-Portfolio should continue to be incorporated as part of the course. Nevertheless, two students voted in opposition: one student felt that using the e-Portfolio posed a disadvantage for less tech-savvy students whereas another student expressed his preference for paper portfolio.

\section{CONCLUSION}

This study aimed to develop an e-Portfolio as an enhanced assessment tool for measuring the writing skills of second language learners at UMS. In this study, the upgrading of assessment from paper portfolio to e-Portfolio was developed systematically based on the ADDIE model. By basing the e-Portfolio's development on the ADDIE model, the researchers were able to take into account the context of assessment and the needs of the learners. This was done by obtaining students' opinions via open-ended questionnaires and analysing samples of students' paper portfolios in the past semester. Apart from that, the views of course instructors were also referred to, thus contributing to a more comprehensive development of the e-Portfolio.

The findings of the pilot test revealed the advantages of using technology-enabled portfolios for academic writing. The students' responses indicated ease in attaining feedback and exchanging comments with instructors and peers. They were also able to explore others' work and include artefacts in their e-Portfolios, thus contributing to a more engaging assessment experience. On the whole, these affordances contributed to improved academic writing skills among the students. Other researchers who have implemented e-Portfolios in higher education context similarly reported positive impact on the respondents' writing performance [24], [25]. Despite the generally positive responses, the pilot test also revealed challenges such as poor Internet connectivity and difficulty adapting to the e-Portfolio. These challenges were likewise reported in other e-Portfolio studies whereby the respondents also cited concerns with Internet connectivity [26] and difficulty in familiarising with the e-Portfolio platform [27]. Although preliminary, this study demonstrated that the e-Portfolio contributed to the development of writing skills among undergraduate students. It also established that the e-Portfolio is a promising assessment tool for second language. In addition, the findings of this study may provide insights to researchers and educators who are keen to adopt e-Portfolio for English language courses.

Despite the relative success of the e-Portfolio in this study, the researchers wish to add that the e-Portfolio can only fulfil its potential and surpass the conventional paper portfolio with the appropriate application. This means that at the very least, instructors must be equipped with sufficient knowledge and skill to use the tool, be able to exemplify e-Portfolio use, and be actively engaged with students to provide feedback and support. Without conviction and investment in using the technology, the e-Portfolio will merely remain as a digital repository.

\section{CONFLICT OF INTEREST}

The authors declare no conflict of interest. 


\section{AUTHOR CONTRIBUTIONS}

Wirawati Ngui conducted the research and analysed the data. All authors contributed to the design of the study and wrote the paper. All authors had approved the final version.

\section{REFERENCES}

[1] S. Grapragasem, A. Krishnan, and A. N. Mansor, "Current trends in Malaysian higher education and the effect on education policy and practice: an overview," International Journal of Higher Education, vol 3 , no. 1, pp. 85-93, 2014.

[2] G. Greenberg, "Extending the portfolio model," EDUCAUSE Review, vol. 39, pp. 28-37, 2004.

[3] G. Lorenzo and J. Ittelson, "An overview of e-portfolios," Educause Learning Initiative, 2005.

[4] D. Challis, "Towards the mature eportfolio: Some implications for higher education," Canadian Journal of Learning and Technology, vol. 31, no. 3, 2005.

[5] H. C. Barrett, "White paper: Researching electronic portfolios and learner engagement," The REFLECT Initiative, pp. 1-25, 2005.

[6] New Zealand Ministry of Education, Digital Portfolios: Guideline for Beginner, Wellington: New Zealand Ministry of Education, 2011.

[7] K. Krause, EPortfolios for Graduate Students: A Discussion Paper, University of Melbourne: Centre For the Study of Higher Education, 2006.

[8] D. Love, G. McKean, and P. Gathercoal, "Portfolios to webfolios and beyond: Levels of maturation," EDUCAUSE Quarterly, vol. 27, no. 2, pp. 24-37, 2004.

[9] K. L. Gustafson and R. M. Branch, Survey of Instructional Development Models, 4th ed., Syracuse, NY: ERIC Clearinghouse on Information and Technology, 2002.

[10] N. Aldoobie, "ADDIE model," American International Journal of Contemporary Research, vol. 5, no. 6, pp. 68-72, 2015.

[11] A. Sharif and S. Cho, "21st century instructional designer: Bridging the perceptual gaps between identity, practice, impact and professional development," RUSC Universities and Knowledge Society Journal, vol. 12, no. 3, pp. 72-85, 2015.

[12] C. Peterson, "Bringing ADDIE to life: Instructional design at its best," Journal of Educational Multimedia and Hypermedia, vol. 12, no. 3, pp 227-241, 2003.

[13] G. Clinton and B. Hokanson, "Creativity in the training and practice of instructional designers: The design/ creativity loops model," Educational Technology Research and Development, vol. 60, no. 1, pp. 111-130, 2012.

[14] R. M. Branch, Instructional Design: The ADDIE Approach, New York: Springer, 2009.

[15] S. E. Kirkley, S. Tomblin, and J. Kirkley, "Instructional design authoring support for the development of serious games and mixed reality training," Interservicel Industry Training Simulaton, and Education Conference (I/ITSEC), pp. 1-11, 2005.

[16] M. Shuib, A. Abdullah, S. N. Azizan, and T. Gunasegaran, "Designing an intelligent mobile learning tool for grammar learning (i-MoL)," International Journal of Interactive Mobile Technologies, vol. 9, no. 1, pp. 41-46, 2015.

[17] G. A. N. Zakaria and A. Nawi, "Design and development of a PBL mobile application in Islamic education: A conceptual framework," International Journal of Information and Education Technology, vol. 10 , no. 1 , pp. 26-30, 2020.

[18] Z. Hua, "How to design and apply interactive digital education tv programs based on the ADDIE model," International Journal of Information and Education Technology, vol. 6, no. 11, pp. 884-889, 2016.

[19] B. Seels, Z, Glasgow, Z. and B. Seels. Making Instructional Design Decisions, Upper Saddle River, NJ: Merrill, 1998.

[20] V. Clarke and V. Braun, "Teaching thematic analysis: Overcoming challenges and developing strategies for effective learning," Psychologist, vol. 26, no. 2, pp. 120-123, 2013.

[21] M. Vaismoradi, H. Turunen, and T. Bondas, "Content analysis and thematic analysis: Implications for conducting a qualitative descriptive study," Journal of Nursing \& Health Sciences, vol.15, pp. 398-405, 2013.

[22] V. Braun and V. Clarke, "Using thematic analysis in psychology," Qualitative Research in Psychology, vol. 3, no. 2, pp. 77-101, 2006.
[23] L. W. Anderson, D. R. Krathwohl, P. W. Airasian, K. A. Cruikshank, R. E. Mayer, P. R. Pintrich, J. Raths, and M. C. Wittrock, A Taxonomy for Learning, Teaching, and Assessing: A Revision of Bloom's Taxonomy of Educational Objectives, New York: Longman, 2001.

[24] J. Kongsuebchart and S. Suppasetseree, "The effect of a weblog-based electronic portfolio on Thai EFL undergraduate students' English writing skills," Computer Assisted Language Learning, vol. 19, no. 2, pp. 28-46, 2018.

[25] R. Wanchid and V. Charoensuk, "The effects of paper-based portfolios and weblog-based electronic portfolios on limited English proficiency students in writing for service industry course," English Language Teaching, vol. 8, no. 9, pp. 131-145, 2015.

[26] M. Rokhsareh, A. R. Azizah, and M. Mojib, "Electronic portfolio motivational factors from students' perspective : A qualitative study," Knowledge Management \& e-Learning, vol. 7, no. 2, pp. 265-279, 2015.

[27] S. M. Thang, Y. S. Lee, and N. F. Zulkifli, "The role of the electronic portfolio in enhancing information and communication technology and English language skills: The voices of six Malaysian undergraduates,' Computer Assisted Language Learning, vol. 25, no. 3, pp. 277-293, 2012 .

Copyright (C) 2020 by the authors. This is an open access article distributed under the Creative Commons Attribution License which permits unrestricted use, distribution, and reproduction in any medium, provided the original work is properly cited (CC BY 4.0).

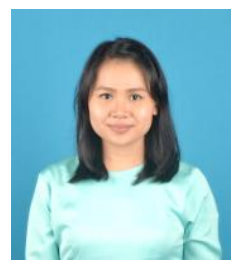

Wirawati Ngui was born in Kuching, Malaysia. She is a PhD student and staff at Universiti Malaysia Sabah Prior to working at Universiti Malaysia Sabah, she served as a secondary school teacher in rural Sarawak, Malaysia.

She completed her undergraduate studies at the University of Auckland in 2011 and received her master's degree from Universiti Malaysia Sabah in 2015. Both degrees were in the field of education, specialising in teaching English as a second language. Her research interests include but are not limited to e-learning and teacher training.

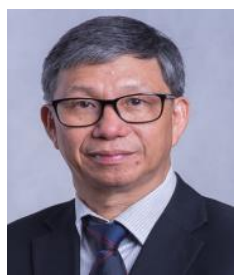

Vincent Pang was born in Muar, Malaysia in 1959 He obtained a doctor of philosophy in curriculum evaluation at RMIT University, Australia in 2002.

He has served as a science teacher for five years, a teacher educator for 9 years, and lecturer/professor for 24 years. Currently he is a professor of Education at the Faculty of Psychology and Education, and the director of the Centre for Teaching Excellence and Academic Quality at Universiti Malaysia Sabah. His current research areas are alternative education program evaluation and higher education.

Prof. Pang is a member of the Malaysian Higher Education Policy and Research Organisation (PENDAPAT) and Qualitative Research Association of Malaysia (QRAM). He is an Advisory Board Member of Asian Journal of University Education, MARA University of Technology and an Editor of the Journal of Psychology and Social Health, Universiti Malaysia Sabah.

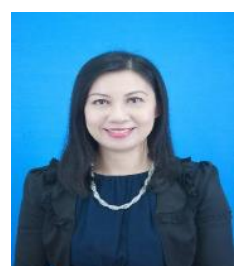

Wendy Hiew was born in Sabah, Malaysia located in the northern part of Borneo. She completed her doctorate in applied linguistics at Macquarie University in Sydney, Australia in April 2017.

She is a senior lecturer at the Centre for the Promotion of Knowledge and Language Learning at Universiti Malaysia Sabah since 2009 and currently heads the Centre's English Language Cluster. She was the former Head of the University's Translation and Editing Unit and was responsible in overseeing the translation and editing work received from various clients within and outside the University. Prior to joining academia, Dr. Wendy taught English language at secondary level for seven years after completing her teaching training in 2002. She has published in various journals and two book chapters including Springer. Her research interests include English language teaching and technology-assisted teaching and learning. 